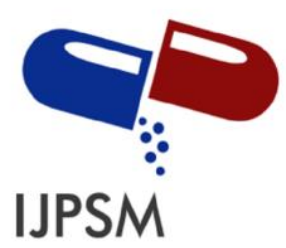

Vijendra Pal Singh Rathore et al, Int. Journal of Pharmaceutical Sciences and Medicine (IJPSM),

Vol.6 Issue. 12, December- 2021, pg. 18-28

ISSN: 2519-9889

Impact Factor: 5.365

\title{
Formulation and Evaluation of Transdermal Patch of Thiochochicoside
}

\author{
Vijendra Pal Singh Rathore; Komal Tikariya; Dr. Jayanti Mukherjee \\ DEPT. OF PHARMACEUTICS, SHRI BHERULAL PHARMACY INSTITUTE, INDORE (M.P) INDIA \\ DOI: 10.47760/ijpsm.2021.v06i12.002
}

\begin{abstract}
The aim of the study is to formulate and evaluate transdermal patches of Thiocholchicoside In the present study, matrix type were prepared by moulding techniques. This mode of drug delivery is more beneficial for chronic disorders such as Rheumatoid arthritis which require long term drug administration to maintain therapeutic drug concentration in plasma. Transport of drugs or compounds via skin is a complex phenomenon, which allows the passage of drugs or compounds into and across the skin. In the present work an attempt has been made to formulate and evaluate the transdermalpatches of Thiocholchicoside using various blends of polymer. The polymeric combinations EC/PVP and EC/HPMC used for the formulation of transdermal patches showed good film forming property. The patches formed were thin, flexible, smooth and transparent. The weight variation tests showed less variation in weight and suggesting uniform distribution of drug and polymer over the mercury surface. The thicknesses of the transdermal patches were found to increase on increasing concentration of hydrophilic polymers like PVP and HPMC.All the patches showed good flexibility and folding endurance properties. The result suggests that the formulations with increased hydrophilic polymer concentration showed long folding endurance. The moisture content in the patches was found to be low and formulations with more hydrophilic polymer concentrations showed more percentage moisture content. The in-vitro drug release studies showed that formulations TDP2, TDP3, TDP4, and TDP5 with increased concentration of hydrophilic polymer showed rapid release. The drug content analysis showed minimum variations suggesting uniform distribution of drug.
\end{abstract}

Keywords:- transdermal patches, Thiocholchicoside, moulding techniques, Rheumatoid arthritis, In-vitro drug release. 


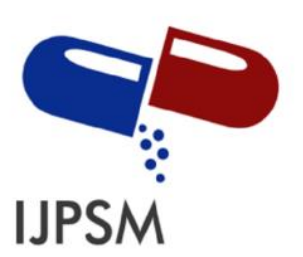

Vijendra Pal Singh Rathore et al, Int. Journal of Pharmaceutical Sciences and Medicine (IJPSM), Vol.6 Issue. 12, December- 2021, pg. 18-28

ISSN: 2519-9889

Impact Factor: 5.365

\section{INTRODUCTION}

Thiocolchicoside binds to GABA-A and strychnine sensitive glycine receptors. Thiocolchicoside acting as a GABA-A receptor antagonist, its myorelaxant effects could be exerted at the supra-spinal level, via complex regulatory mechanisms, although a glycinergic mechanism of action cannot be excluded. The characteristics of the interaction of Thiocolchicoside with GABA-A receptors are qualitatively and quantitatively shared by its main circulating metabolite, the glucuronidated Derivative. Thiocolchicoside is rapidly absorbed after oral administration, and metabolized into 3 main metabolites. The two main circulating forms were the Thiocolchicoside aglycon and the glucuronidated derivative of Thiocolchicoside, which is active. Thiocolchicoside is well tolerated oral administration for periods of up to 6 months

Transdermal delivery of drugs through the skin to the systemic circulation provides a convenient route of administration for a variety of clinical indications. Several TDDS containing drugs such as clonidine, estradiol, fentanyl, nicotine, nitroglycerin, oxybutynin and scopoloamine are available in the United States. This mode of drug delivery is more beneficial for chronic disorders such as Rheumatoid arthritis which require long term drug administration to maintain therapeutic drug concentration in plasma. Transport of drugs or compounds via skin is acomplex phenomenon, which allows the passage of drugs or compounds into and across the skin. The skin is one of the most extensive and readily accessible organs of the human body. It receives about one-third of the blood circulation through the body. Hence the skin has been explored as the port of entry of drugs. Innovations in the area of drug delivery are taking place at a much faster pace as compared to the last two decades. Though these drugs re absorbed orally their bioavailability varies widely because of extensive presystemic metabolism. In the transdermal matrix drug delivery system the polymer matrix binds with the drug and controlsthe release of the drug from the patch.(eg : Nitrodur, Duragesic)

Transdermal drug delivery has been investigated and developed in order to

- Avoid hepatic first pass effect.

- Minimize fluctuations in plasma drug concentration.

- Improve drug bioavailability.

- Reduce dosing frequency and improve patient compliance.

The main aim of current research is to formulate and evaluate Transdermal Patch of Thiochochicoside 


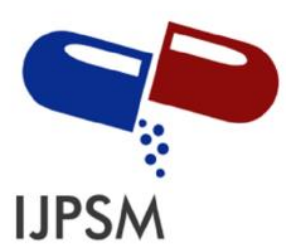

Vijendra Pal Singh Rathore et al, Int. Journal of Pharmaceutical Sciences and Medicine (IJPSM), Vol.6 Issue. 12, December- 2021, pg. 18-28

ISSN: 2519-9889

Impact Factor: 5.365

\section{MATERIALS AND METHOD}

\section{MATERIALS}

Thiochochicoside working standard was kindly provided by Alembic Ltd., (Vadodara, India) and was used as red. A commercial capsule formulation was purchased from the local market. Sodium hydroxide $(0.1 \mathrm{~N})$ of analytical grade solution was prepared in double distilled water.

\section{EXPERIEMENTALS}

\subsection{Identification of Drug}

\subsubsection{By UV Spectroscopy}

A double beam UV-VIS spectrophotometer (UV-1800, Shimadzu, Japan) connectedto computer loaded with spectra manager software UV Probe was employed with spectralbandwidth of $1 \mathrm{~nm}$ and wavelength accuracy of $\pm 0.3 \mathrm{~nm}$ with a pair of $10 \mathrm{~mm}$ matched quartz cells. All weights were taken on electronic balance (Denver, Germany). Preparation of Standard Stock Solution The standard solution of THC was prepared by dissolving accurately weighed $10 \mathrm{mg}$ of the drug in $0.1 \mathrm{~N} \mathrm{NaOH}$ and diluted to $100 \mathrm{ml}$ with $0.1 \mathrm{~N} \mathrm{NaOH}$ to obtain a finalconcentration of $100 \mu \mathrm{g} \mathrm{ml}-1$. This stock solution was used to prepare further dilutions of standard solutions. Series dilutions of the stock solution were made by pipetting out $0.25,0.5,1.0,2.0,4.0$ and 5.0 $\mathrm{ml}$ stock solution into separate $10 \mathrm{ml}$ volumetric flasks and diluting to volume with $0.1 \mathrm{~N} \mathrm{NaOH}$ to produce the concentrations ranging from 2.5-50.0 $\mu \mathrm{g}$ ml-1. The above solutions were scanned over the range of $400 \mathrm{~nm}$ to $200 \mathrm{~nm}$ against blank.

\subsubsection{Preparation of standard calibration curve of Thiochochicoside}

Aliquots of standard stock solution were diluted with water to get a series of concentration of standard drug in the range of $2.5-50 \mu \mathrm{g} / \mathrm{mL}$ and scanned in the spectrum mode from the wavelength range 400-200 $\mathrm{nm}$. Calibration curve was plotted as absorbance Vs concentration. 


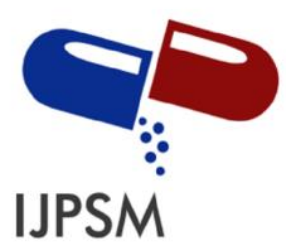

Vijendra Pal Singh Rathore et al, Int. Journal of Pharmaceutical Sciences and Medicine (IJPSM),

Vol.6 Issue. 12, December- 2021, pg. 18-28

ISSN: 2519-9889

Impact Factor: 5.365

\section{FORMULATION OF TRANSDERMAL PATCHES OF THIOCHOCHICOSIDE}

In the present study, matrix type transdermal patches of Thiochochicoside were prepared by moulding techniques. A flat circular glass moulds having diameter $4.5 \mathrm{~cm}$ and height of $1 \mathrm{~cm}$ with a total surface area of $15.91 \mathrm{~cm} 2$ was fabricated for this purpose.

a) PREPARATION OF CASTING SOLUTIONS: The casting solutions were prepare by dissolving weighed quantities of polymers in a solvent mixture of chloroform and methanol at 1:1 ratio. The drug, plasticizer and permeation enhancers were then added to the various polymer solutions individually and thoroughly mixed to from a homogenous mixture it was placed aside without any disturbances to allow the entrapped air to bubble out.

b) PREPARATION OF TRANSDERMAL PATCHES: About $3 \mathrm{ml}$ of casting solutions were pipetted into circular glass moulds especially designed to hold contents, which is casted on mercury surface. The glass moulds containing the casting solutions were allowed for drying at room temperature for $24 \mathrm{hrs}$ and the patches are dried in over at $40-45^{\circ}$ for 30 minutes in order toremove the residual solvents. The patches were removed and cut into circular discs with $4.4 \mathrm{~cm}$ diameter $(15.21 \mathrm{~cm} 2$ surface area). These patches were wrapped in aluminum foil and stored in dessicator for further studies.

COMPOSITIONS OF TRANSDERMAL PATCHES OF THIOCHOCHICOSIDE

\begin{tabular}{|c|c|c|c|c|c|c|c|c|c|}
\hline Ingredients & $\mathbf{T D P}_{\mathbf{1}}$ & $\mathbf{T D P}_{\mathbf{2}}$ & $\mathbf{T D P}_{\mathbf{3}}$ & $\mathbf{T D P}_{\mathbf{4}}$ & $\mathbf{T D P}_{\mathbf{5}}$ & $\mathbf{T D P 6}$ & $\mathbf{T D P 7}$ & $\mathbf{T D P}_{\mathbf{8}}$ & $\mathbf{T D P}_{\mathbf{9}}$ \\
\hline $\begin{array}{c}\text { Thiocholchicoside } \\
(\mathrm{Mg})\end{array}$ & 10 & 10 & 10 & 10 & 10 & 10 & 10 & 10 & 10 \\
\hline $\begin{array}{c}\text { Hydroxyl Propyl } \\
\text { Methyl Cellulose } \\
\text { in Parts }\end{array}$ & 4.5 & 4 & 3.5 & 3 & 2.5 & 2 & 1 & 4.5 & 4 \\
\hline $\begin{array}{c}\text { Ethyl Cellulose } \\
\text { in Parts }\end{array}$ & 4.5 & 4 & 3.5 & 2.5 & 2 & 1.5 & 1 & 0.5 & 1 \\
\hline Eudragit in parts & 0.5 & 1 & 1.5 & 2 & 2.5 & 3 & 4 & - & - \\
\hline
\end{tabular}




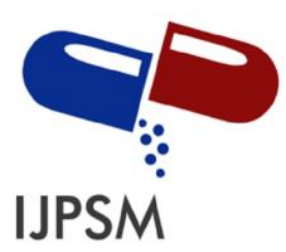

Vijendra Pal Singh Rathore et al, Int. Journal of Pharmaceutical Sciences and Medicine (IJPSM), Vol.6 Issue. 12, December- 2021, pg. 18-28

ISSN: 2519-9889

Impact Factor: 5.365

\begin{tabular}{|c|c|c|c|c|c|c|c|c|c|}
\hline $\begin{array}{c}\text { Glycerol in \% } \\
\text { w/w }\end{array}$ & 30 & 30 & 30 & 30 & 30 & 30 & 30 & 30 & 30 \\
\hline DMSO in w/w & 20 & 20 & 20 & 20 & 20 & 20 & 20 & 20 & 20 \\
\hline
\end{tabular}

\section{EVALUATION OF TRANSDERMAL PATCHES OF THIOCHOCHICOSIDE}

\subsection{Patches Physical appearance}

All the transdermal patches are visually inspected for color, clarity, flexibility and smoothness.

\subsection{Weight uniformity}

Four patches from each batch are accurately weighed using a digital balance. The average weightand the standard deviation values are calculated from the individual weights.

\subsection{Thickness of the films}

The thicknesses of the drug loaded polymeric films are measured using a digital vernier caliper. The measurements are made at five different points, four at the corners and one at the centre of the patch. The average and standard deviation of five readings were calculated for each formulation.

\subsection{Folding endurance}

Folding endurance of patches is determined by repeatedly folding the small strip of film at the same place till it breaks. The number of times, the film could be folded at the same place till it breaks will give the value of folding endurance.

\subsection{Percentage moisture content}

The prepared films are weighed individually and kept in a desiccator containing silica gel at room temperature for 24 hours. The films were again weighed and the percentage moisture content is calculated using the formula:

Percentage moisture content $=[($ Initial weight - Final weight $) /$ Final weight $] \times 100$

\subsection{Estimation of drug content}

Transdermal patches of specified area and weight are cut into small pieces and are transferred into $100 \mathrm{~mL}$ standard flask. About $5 \mathrm{~mL}$ of methanol is added to dissolve the patch and then made upto 


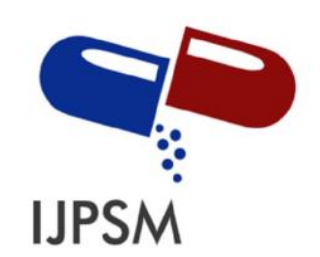

Vijendra Pal Singh Rathore et al, Int. Journal of Pharmaceutical Sciences and Medicine (IJPSM), Vol.6 Issue. 12, December- 2021, pg. 18-28

ISSN: 2519-9889

Impact Factor: 5.365

$100 \mathrm{~mL}$ with methanolic isotonic phosphate buffer $\mathrm{pH}$ 7.4. Similarly, a blank is also prepared using drug free patch. The solutions are filtered and the absorbance is measured using UV visible spectrophotometer.

\subsection{Determination of Tensile Strength}

The instrument, which was designed in our laboratory, was used for the measurement of tensile strength. The strip was clamped at the static end and was attached to the movable rod on a railing with the help of a clip. The weights were gradually added to the pan to increase the pull force till the film was cut. The elongation was determined simultaneously by noting the distance traveled by the pointer, before break of the film, on the graph paper. The weight required to break the film was noted as the break force. The tensile strength was calculated using Allen"s formula.

TENSILE STRENGTH $=$ BREAK FORCE $\mathrm{x}(1+\Delta \mathrm{L}) \mathrm{a} \times \mathrm{b} \mathrm{L}$

\subsection{In-vitro drug release studies}

The in-vitro drug release study for the transdermal patches are carried out using modified paddle over disc assembly USP 23, Apparatus 5. The disc apparatus consists of mesh screen made of stainless steel clamped in the watch glass using nylon clips.

The transdermal patch of area $3.14 \mathrm{~cm} 2$ is pasted over a small piece of aluminium foil (backing layer) to prevent two dimensional releases. The transdermal patch with backing layer is placed between inert stainless steel mesh and watch glass exposing the patch to the medium. It is also ensured that the patch does not float inside the disc assembly.

The disc assembly containing transdermal patch is placed at the bottom of the dissolution vessel, with the mesh facing upwards, under the rotating paddle. The dissolution medium used is $900 \mathrm{ml}$ of methanolic isotonic phosphate buffer $\mathrm{pH}$ 7.4. The apparatus was equilibrated to the temperature of 37 $\pm 0.50 \mathrm{c}$ operated at $50 \pm 1 \mathrm{rpm}$. The dissolution study is carried out for 12 hours. $10 \mathrm{ml}$ of samples are withdrawn at regular intervals of 1 hour and the same volume of corresponding dissolution medium was replenished to maintain sink condition. The amount of Thiochochicoside released is determined by measuring the absorbance of thesamples using UV-Visible spectrophotometer. Each test is performed in triplicate. 


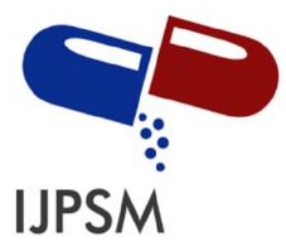

Vijendra Pal Singh Rathore et al, Int. Journal of Pharmaceutical Sciences and Medicine (IJPSM), Vol.6 Issue. 12, December- 2021, pg. 18-28

ISSN: 2519-9889

Impact Factor: 5.365

\section{RESULT AND DISCUSSION}

\subsection{Identification of drug}

Series dilutions of the stock solution were made by pipetting out $0.25,0.5,1.0,2.0,4.0$ and $5.0 \mathrm{ml}$ stock solution into separate $10 \mathrm{ml}$ volumetric flasks and diluting to volume with $0.1 \mathrm{~N} \mathrm{NaOH}$ to produce the concentrations ranging from 2.5-50.0 $\mu \mathrm{g} \mathrm{ml-1.} \mathrm{The} \mathrm{above} \mathrm{solutions} \mathrm{were} \mathrm{scanned} \mathrm{over}$ the range of $400 \mathrm{~nm}$ to $200 \mathrm{~nm}$ against blank. The $\lambda$ max was found to be at 259.0 and $374.0 \mathrm{~nm}$
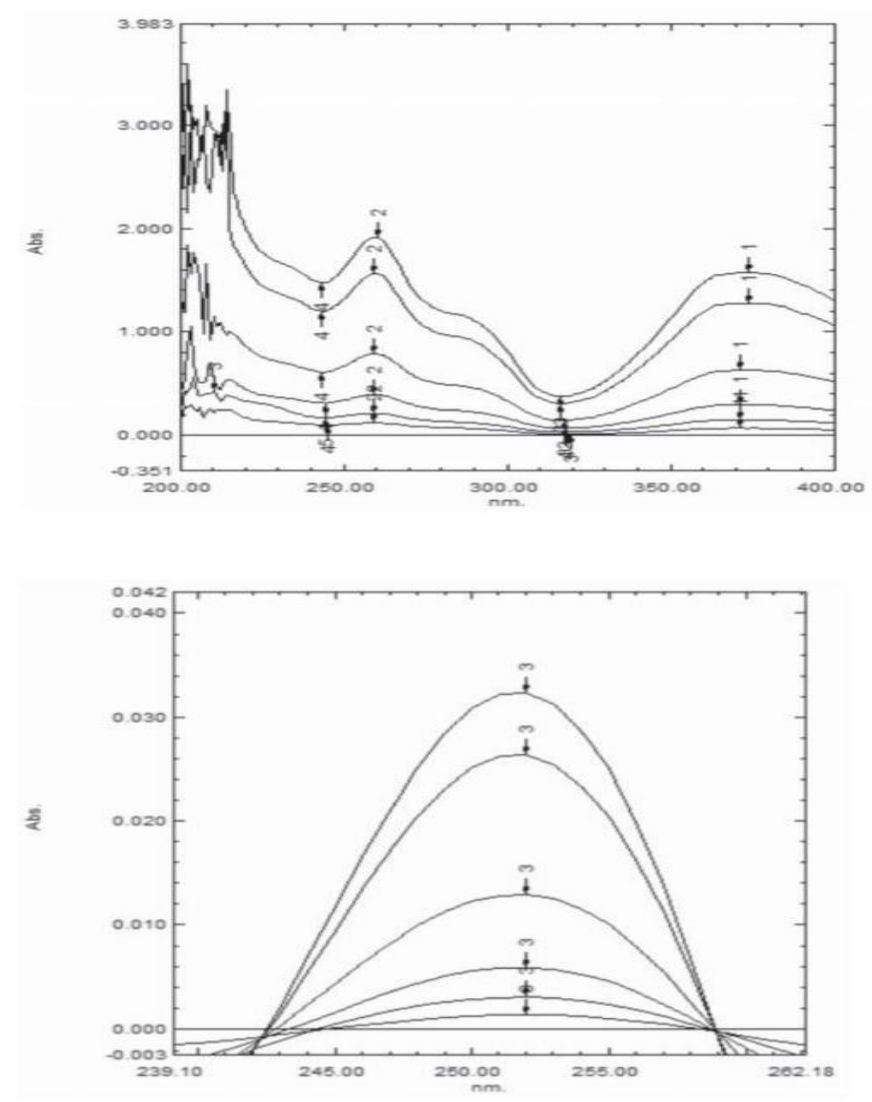


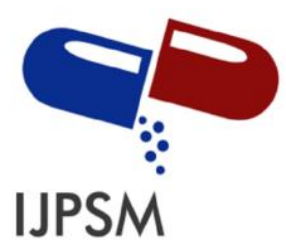

Vijendra Pal Singh Rathore et al, Int. Journal of Pharmaceutical Sciences and Medicine (IJPSM), Vol.6 Issue. 12, December- 2021, pg. 18-28

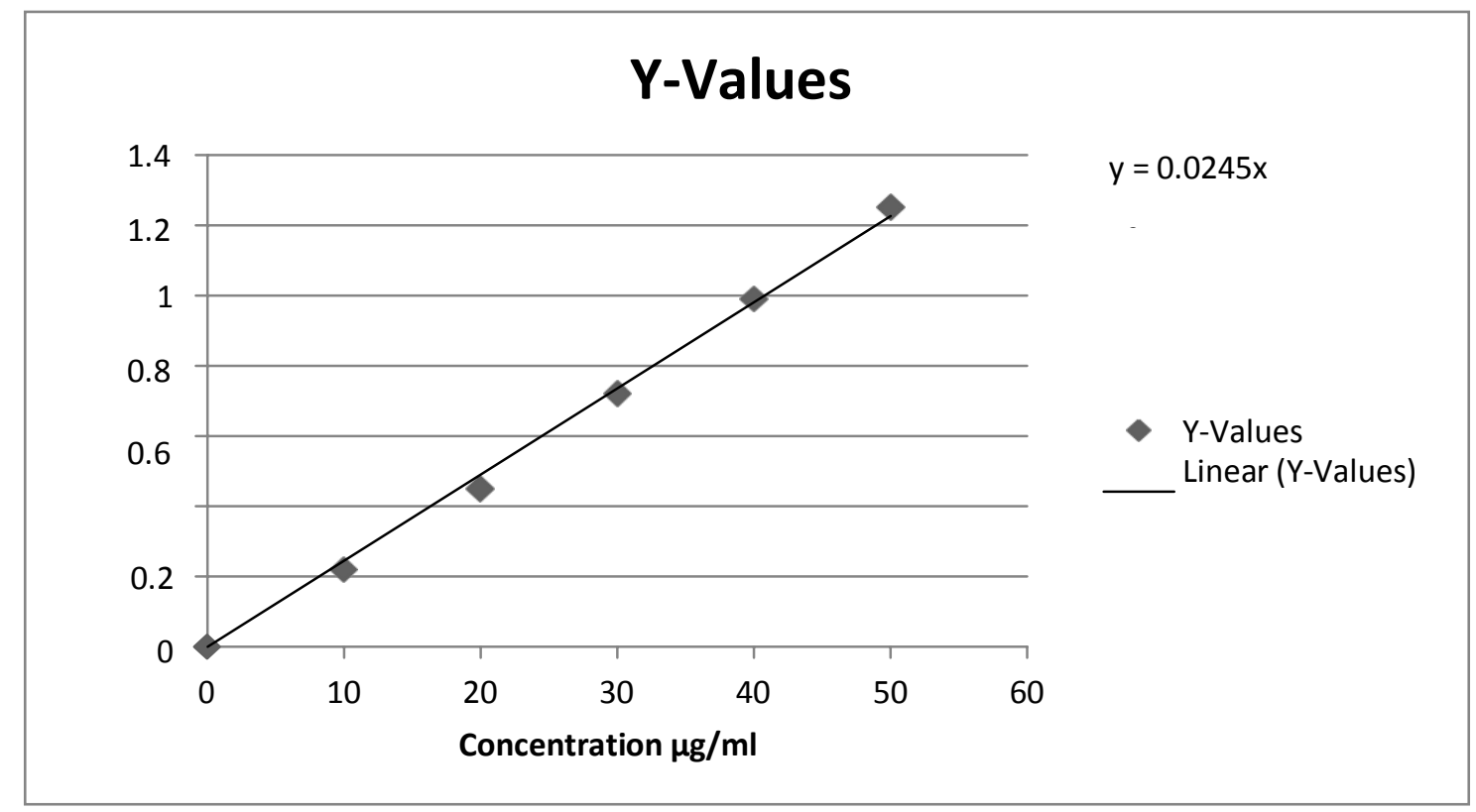

Fig 5: Calibration curve of Thiochochicoside

\subsubsection{Preparation of Standard Calibration Curve of Thiochochicoside}

Aliquots of standard stock solution were diluted with water to get a series of concentration of standard drug in the range of $2.5-50 \mu \mathrm{g} / \mathrm{mL}$ and scanned in the spectrum mode from the wavelength range $400-200 \mathrm{~nm}$. Calibration curve was plotted as absorbance Vs concentration.

\subsection{Evaluation Parameters:}

\subsubsection{Physical appearance}

All the polymers used for the formulation of transdermal patches showed good film forming properties. The patches formed were thin, flexible, smooth and transparent. The method used for casting the film on a mercury substrate was found to be satisfactory.

\subsubsection{Weight uniformity}

The results of weight variation tests of the patches are shown in the table-2. The weights of the patches ranged from $246.36 \pm 1.46 \mathrm{mg}$ to $482.24 \pm 1.15 \mathrm{mg}$ for EC/PVP formulations and $237.23 \pm 0.64 \mathrm{mg}$ to $467.02 \pm 0.65 \mathrm{mg}$ for EC/HPMC formulations. From the results it has been found that there is less variation in weight between different patches of a same batch suggesting uniform distribution of drug and polymer over the mercury surface. 


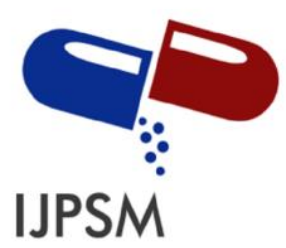

Vijendra Pal Singh Rathore et al, Int. Journal of Pharmaceutical Sciences and Medicine (IJPSM), Vol.6 Issue. 12, December- 2021, pg. 18-28

ISSN: 2519-9889

Impact Factor: 5.365

\subsubsection{Thickness of the patches}

The results of thickness of the patches are shown in the table-3. The thickness of the patch ranged from $0.078 \pm 0.007 \mathrm{~mm}$ to $0.148 \pm 0.009 \mathrm{~mm}$ for formulations prepared with EC/PVP and $0.069 \pm 0.004 \mathrm{~mm}$ to $0.131 \pm 0.015 \mathrm{~mm}$ for formulations prepared with EC/HPMC. From the results it was found that thickness increases with increase in concentration of hydrophilic polymers (PVP and HPMC). The thickness of the patch over five different areas was found to be uniform, suggesting even distribution of drug and polymer over the mercury surface.

\subsubsection{Folding endurance}

The results of folding endurance were shown in table-3. The folding endurance of EC/PVP patches ranged from $14.33 \pm 0.471$ to $27.66 \pm 2.624$ and that of EC/HPMC patches ranged from $11.66 \pm 2.054$ to $26.66 \pm 2.054$ respectively. The results from the table also showed that increasing concentration of hydrophilic polymers showed increasing folding endurance. All the patches showed good flexibility and folding endurance properties.

\subsubsection{Estimation of drug content}

The results of drug content analysis were shown in table-5. The drug content of the patches ranged from $96.45 \pm 0.942 \%$ to $100.76 \pm 1.414 \%$. The results suggest that the method employed to prepare the patches shown uniformity in drug content with minimum variations and also the results showed that the drug has been uniformly distributed.

\subsubsection{In-vitro drug release studies}

The results of in-vitro drug release studies from the transdermal patches are shown in the tables- $6,7,8,9,10,11$ and in figures $9,10,11,12,13$ and 14 respectively. The formulations with total polymer weight $200 \mathrm{mg}$ containing EC/PVP in the ratio $(3: 2)$ and EC/HPMC in the ratio (3:2) exhibited greatest (100.82 \pm 3.78 and $89.25 \pm 1.93$ respectively) percentage of drug release in 12 hours, whereas lowest release were observed with the formulations with total polymer weight $400 \mathrm{mg}$ containing EC/PVP in the ratio (4.5:0.5) and EC/HPMC in the ratio (4.5:0.5) (46.14 \pm 2.47 and $46.73 \pm 1.34$ respectively) in 12 hours.

\section{CONCLUSION}

The sustained release of drug from the transdermal patches suggests that the frequency of administration may be reduced. Further, the transdermal patches may improve the bioavailability of the drug by avoiding hepatic first pass metabolism. Hence we can conclude that the polymer matrix provide sustained delivery of drug and these systems can be used to deliver drugs with short half-life and low therapeutic index through transdermal drug delivery systems.

- In the present work an attempt has been made to formulate and evaluate the transdermalpatches of Thiocholchicoside using various blends of polymer.

- The polymeric combinations EC/PVP and EC/HPMC used for the formulation of transdermalpatches showed good film forming property.

- The patches formed were thin, flexible, smooth and transparent. 


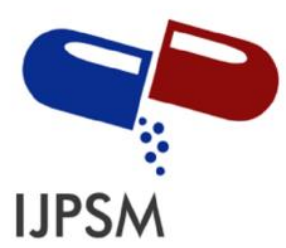

Vijendra Pal Singh Rathore et al, Int. Journal of Pharmaceutical Sciences and Medicine (IJPSM), Vol.6 Issue. 12, December- 2021, pg. 18-28

- The weight variation tests showed less variation in weight and suggesting uniform distribution of drug and polymer over the mercury surface.

- The thicknesses of the transdermal patches were found to increase on increasing concentration of hydrophilic polymers like PVP and HPMC.

- All the patches showed good flexibility and folding endurance properties. The result suggests that the formulations with increased hydrophilic polymer concentration showed long folding endurance.

- The moisture content in the patches was found to be low and formulations with more hydrophilic polymer concentrations showed more percentage moisture content.

- The in-vitro drug release studies showed that formulations TDP2, TDP3, TDP4, and TDP5with increased concentration of hydrophilic polymer showed rapid release.

- The drug content analysis showed minimum variations suggesting uniform distribution of drug.

\section{ACKNOWLEDGEMENT}

The author is thankful to the management of Shri Bherulal pharmacy institute, Indore. For providing necessary facilities to carry out the research work and heartily thankful to my guide Dr. Jayanti Mukherjee and my Co-Guide Ms. Komal Tikariya for providing all the support and encouragement to carry out this studies.

\section{REFERENCES}

[1]. Bala P. Jather S.,Kale S., and Pal K. Transdermal Drug Delivery System (TDDS) - A Multifaceted Approach For Drug Delivery, Journal of Pharmacy Research 2014,8(12),1805- 1835.

[2]. Bei D, Marszalek J, Youan BBC 2017. Formulation of dacarbazine loaded cubosomespart II: Influence of process parameters. AAPS Pharm Sci Tech. 10: 1040-1046.

[3]. Evane B., Singh S., and Pathak AK, Formulation and Evaluation of Transdermal Drug Delivery System of Simvastatin. Journal of Pharmacy Research. 2012,5(2),810-813.

[4]. Fatima A., and Begam S., Transdermal Drug Delivery System, International Journal of Pharmaceutical and Clinical Research 2017; 9(1): 35-43.

[5]. Idrees A., Rahman U., and Kasif M., In Vitro Evaluation Of Transdermal Patches Of Flurbiprofen With Ethyl Cellulose Acta Poloniae Pharmaceutica ñ Drug Research, Vol. 71 No. 2 pp. 287-295, 2014.

[6]. Kriplani P., Sharma A., Formulation and Evaluation of Transdermal Patch of Diclofenac Sodium Glob J Pharmaceu Sci 4(5): GJPPS.MS.ID.555647 (2018).

[7]. Pasha K., and Banu S.,, Formulation and Evaluation of Transdermal Patches of 


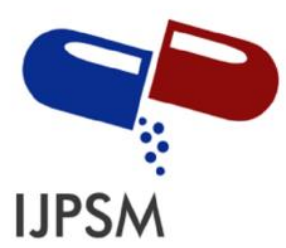

Vijendra Pal Singh Rathore et al, Int. Journal of Pharmaceutical Sciences and Medicine (IJPSM), Vol.6 Issue. 12, December- 2021, pg. 18-28

Glibenclamide International Journal of Research in Pharmacy and Biosciences Volume 4, Issue 7, 2017, PP 29-32.

[8]. Patel A., and Solanki R Formulation, Development and Evaluation of Etoricoxib containing Transdermal patches in Arthritis management. International Journal of Research and Analytical Reviews, OLUME 5 I ISSUE 4 I OCT.- DEC. 2018.

[9]. Sourabh A., and Atul S., Formulation and Development of Transdermal Patches of Piroxicam, Asian Journal of Pharmaceutical Research and Development. 2019; 7(3):119- 128.

[10]. Fairhurst DA, et al. Optimal management of severe plaque form of psoriasis. Am J Clin Dermatol 2011; 6: 283-94.

[11]. . Sharma, S.,2008. Topical Preparations are Used for the Localized Effects at the Site of Their Application By Virtue of Drug Penetration Into the Underlying Layers of Skin Or Mucous Membranes. Pharmaceutical Reviews 6:1-10.

[12].Satyanarayana , S.V., Gupta,M., Kahal,J.K., Agrawal,A.,Marwara,R.K.,2008. Evaluation of Topical Gels Containing Non Steroidal Anti-Inflammatory Drugs on Inflammation and Hyperalgesia In Rats. The Internat Journal Of Pharmacology 6:1531-1576.

[13]. Gelfand JM et al. (2005). "Prevalence and Treatment of Psoriasis in the United Kingdom". Arch. Dermatol. 141 (12): 1537-1541.

[14]. Krueger G, Ellis CN (2005). "Psoriasis--recent advances in understanding its pathogenesis and treatment". J. Am. Acad. Dermatol. 53 (1 Suppl 1): S94-100.

[15]. Keleb E, Sharma RK, Mosa EB, Aljahwi AZ. Transdermal Drug Delivery SystemDesign and Evaluation. International Journal of Advances in Pharmaceutical Sciences 2010; 1: 201-211.

[16]. Schofield OMV, Rees JL. Skin disease, In Hunter J editor, Devidsins principle and practices of medicine, 19th edition, Churchill Livingstone, , 2002, pp 1049-1055.

[17]. Vyas SP, Khar RK. Controlled Drug Delivery: Concepts and Advances, first edition, Vallabh Prakashan, 2002, pp 411-447. 